\title{
THE
}

\section{2,6-hexadecadiynoic acid and 2,6-nonadecadiynoic acid: Novel synthesized acetylenic fatty acids as potent antifungal agents}

\author{
Néstor M. Carballeira \\ David Sanabria \\ Clarisa Cruz \\ Keykavous Parang \\ University of Rhode Island, kparang@uri.edu \\ Baojie Wan
}

See next page for additional authors

Follow this and additional works at: https://digitalcommons.uri.edu/bps_facpubs

This is a pre-publication author manuscript of the final, published article.

Terms of Use

All rights reserved under copyright.

\section{Citation/Publisher Attribution}

Carballeira, N. M., Sanabria, D. , Cruz, C. , Parang, K. , Wan, B. and Franzblau, S. (2006),

2,6-hexadecadiynoic acid and 2,6-nonadecadiynoic acid: Novel synthesized acetylenic fatty acids as potent antifungal agents. Lipids, 41: 507-511. doi: 10.1007/s11745-006-5124-4

Available at: https://doi.org/10.1007/s11745-006-5124-4

This Article is brought to you for free and open access by the Biomedical and Pharmaceutical Sciences at DigitalCommons@URI. It has been accepted for inclusion in Biomedical and Pharmaceutical Sciences Faculty Publications by an authorized administrator of DigitalCommons@URI. For more information, please contact digitalcommons-group@uri.edu. 
Authors

Néstor M. Carballeira, David Sanabria, Clarisa Cruz, Keykavous Parang, Baojie Wan, and Scott Franzblau

This article is available at DigitalCommons@URI: https://digitalcommons.uri.edu/bps_facpubs/174 
Published in final edited form as:

Lipids. 2006 May ; 41(5): 507-511.

\title{
2,6-Hexadecadiynoic Acid and 2,6-Nonadecadiynoic Acid - Novel Synthesized Acetylenic Fatty Acids as Potent Antifungal Agents
}

\author{
Néstor M. Carballeiraa, ${ }^{*}$, David Sanabriaa ${ }^{a}$, Clarisa Cruz ${ }^{a}$, Keykavous Parang ${ }^{b}$, Baojie Wanc, \\ and Scott Franzblauc \\ a Department of Chemistry, University of Puerto Rico, PO Box 23346, San Juan, Puerto Rico \\ 00931-3346, \\ b Department of Biomedical and Pharmaceutical Sciences, College of Pharmacy, University of \\ Rhode Island, Kingston, Rhode Island, USA 02881, and \\ c Institute for Tuberculosis Research, College of Pharmacy, The University of Illinois at Chicago, \\ Chicago, Illinois 60612-7231
}

\begin{abstract}
The hitherto unknown 2,6-hexadecadiynoic acid, 2,6-nonadecadiynoic acid, and 2,9-

hexadecadiynoic acid were synthesized in two steps and in 11-18\% overall yields starting from either 1,5-hexadiyne or 1,8-nonadiyne. Among all the compounds 2,6-hexadecadiynoic acid displayed the best overall antifungal activity against both the fluconazole resistant Candida albicans strains ATCC 14053 and ATCC $60193(\mathrm{MIC}=11 \mu \mathrm{M}$ ) and against Cryptococcus neoformans ATCC 66031 (MIC $<5.7 \mu \mathrm{M})$. The 2,9-hexadecadiynoic acid did not display any significant cytotoxicity against the fluconazole resistant $C$. albicans strains, but it showed fungitoxicity against $C$. neoformans ATCC 66031 with a MIC value of $<5.8 \mu \mathrm{M}$. Other fatty acids, such as 2-hexadecynoic acid, 5-hexadecynoic acid, 9-hexadecynoic acid, and 6-nonadecynoic acid were also synthesized and their antifungal activities compared. The 2-hexadecynoic acid, a known antifungal fatty acid, exhibited the best antifungal activity $(\mathrm{MIC}=9.4 \mu \mathrm{M})$ against the fluconazole resistant $C$. albicans ATCC 14053 strain, but it showed a MIC value of only $100 \mu \mathrm{M}$ against $C$. albicans ATCC 60193. The fatty acids 2,6hexadecadiynoic acid and 2-hexadecynoic acid also displayed a MIC of 140-145 $\mu \mathrm{M}$ towards Mycobacterium tuberculosis $\mathrm{H}_{37} \mathrm{Rv}$ in Middlebrook $7 \mathrm{H} 12$ medium. In conclusion, 2,6hexadecadiynoic acid exhibited the best fungitoxicity profile compared to other analogues. This diynoic fatty acid has the potential to be further evaluated for use in topical antifungal formulations.
\end{abstract}

The 2-alkynoic fatty acids (FA) have been known to be fungitoxic (1-2). The fungal activity of these compounds depends on the FA chain length and $\mathrm{pH}$ of the medium (1-2). The optimal chain lengths between 8 and 16 carbons have been established for the 2-alkynoic FA to exert maximum fungistatic effects (2). Among the 2-alkynoic FA the 2-hexadecynoic acid has received the most attention for its antifungal, antimicrobial, and cytotoxic properties (3-5). The bioactivity of the 2-hexadecynoic acid has been ascribed to its ability to inhibit the elongation of saturated and unsaturated FA as well as its potential to inhibit the FA acylation process, particularly triglyceride synthesis (4-5).

Other isomeric alkynoic FA, in particular the 6-alkynoic FA, are also fungistatic. For example, when an unsaturation is introduced between C- 6 and C-7 in a fatty acyl chain the FA displays good fungitoxicity. It is shown that 6-hexadecynoic acid is a good substrate for the enzyme myristoyl-CoA:protein $N$-myristoyltransferase from Saccharomyces cerevisiae, an important

*To whom correspondence should be addressed. Tel.: (787)-764-0000, ext. 4791. Fax: (787)-756-8242. E-mail: nmcarballeira@uprrp.edu.. 
enzyme for fungal growth and a good target for antifungal therapy (6). Furthermore, 6nonadecynoic acid, recently isolated from the roots of Pentagonia gigantifolia, is reported to be fungistatic against some fungal strains of fluconazole resistant Candida albicans (7) as well as to Cryptococcus neoformans (8). C. albicans and C. neoformans are pathogenic fungi of concern in immunocompromised patients. On the other hand, 6-alkenoic FA have been also evaluated. For example, the 6-hexadecenoic acid is antimicrobial to gram-positive bacteria (MIC's of 10-20 $\mu \mathrm{g} / \mathrm{ml}$ ) and blocks the adherence of C. albicans to porcine stratum corneum (9).

With this information at hand regarding the antifungal activities of 2-alkynoic and 6-alkynoic FA, we envisaged the possibility of combining in a single molecule the C-2 and C- 6 ynoic functionalities, i.e., by synthesizing 2,6-diynoic FA and evaluating their antifungal properties. It was expected that novel 2,6-diynoic FA to have a better antifungal profile than either of the parent 2-alkynoic or 6-alkynoic FA. The synthesis of 2,6-octadecadiynoic acid as a precursor to furan-containing FA has been previously reported by Lie Ken Jie et. al. (10-11). However, to the best of our knowledge, the FA 2,6-hexadecadiynoic acid (3a) and 2,6-nonadecadiynoic acid (3c) are novel. We describe the synthesis of the dimethylene-interrupted diynoic FA 3a and $\mathbf{3 c}$, as well as the synthesis of the 2,9-hexadecadiynoic acid (3b). Comparative antifungal activities of the compounds indicated that $\mathbf{3 a}$ had the best fungitoxicity profile among the studied compounds and the known 2-hexadecynoic acid.

\section{MATERIALS AND METHODS}

\section{Instrumentation}

${ }^{1} \mathrm{H}$ and ${ }^{13} \mathrm{C}$ NMR spectra were recorded on either a Bruker DPX-300 or a Bruker DRX-500 spectrometer. ${ }^{1} \mathrm{H}$ NMR chemical shifts are reported with respect to internal $\mathrm{Me}_{4} \mathrm{Si}$ and chemical shifts are given in parts per million (ppm) relative to $\mathrm{CDCl}_{3}(77.0 \mathrm{ppm})$. Mass spectral data was acquired on a GC-MS (Hewlett-Packard 5972A MS ChemStation) instrument at $70 \mathrm{eV}$, equipped with a $30 \mathrm{~m} \times 0.25 \mathrm{~mm}$ special performance capillary column (HP-5MS) of polymethylsiloxane cross-linked with 5\% phenyl methylpolysiloxane. Infrared spectra were recorded on a Nicolet 600 FT-IR spectrophotometer.

\section{Microorganisms}

C. albicans ATCC 60193, C. albicans ATCC 14053, and C. neoformans ATCC 66031 were obtained from American Type Culture Collection, Manassas, Virginia, USA. Stock cultures were kept on Sabouraud Dextrose Agar (SDA; Becton-Dickinson and Co., Sparks, Maryland). Subcultures were prepared on SDA at $35-37^{\circ} \mathrm{C}$. Suspension cultures were prepared by inoculation of single colonies in $7 \mathrm{ml}$ of normal saline solution. Prior to preparation of susceptibility assays, yeast cells were resuspended in normal saline to make a transmittance of $73-75 \%$ at $530 \mathrm{~nm}$ that provide equivalent concentration of $10^{6}$ cells $/ \mathrm{ml}$. The media was Sabourand dextrose broth (SDB; Becton Dickinson and Co., Sparks, Maryland).

\section{Chemicals and Antifungal Agents}

Amphotericin B (AMB) was purchased from Acros, New Jersey, USA, and was kept as a 5 $\mathrm{mM}$ stock in DMSO at $0^{\circ} \mathrm{C}$ and used during one week of preparation. Fluconazole (FLC) was purchased from Medisa Inc., New York, NY, USA, or was provided from Vera Laboratories Ltd, Hyderabad, India, and was kept as a $20 \mathrm{mM}$ stock solution at $0^{\circ} \mathrm{C}$. Working dilutions were made in SDB medium. Higher concentrations of compounds were used for those with weak antifungal activities. The final maximum concentration of DMSO in the assays was $5 \%(\mathrm{v} / \mathrm{v})$. DMSO was not inhibitory to the organisms tested. 


\section{Susceptibility Testing}

Microdilutions for control experiments with C. albicans and C. neoformans were performed according to the modified method of National Committee for Clinical Laboratory Standards (NCCLS) method as described by Galgiani (12) and according to the more recent NCCLS M27-A microdilution methods as described previously (13-14). Dilutions were prepared in $0.1 \mathrm{ml}$ of SDB; the inocula were either $10^{4}$ C. albicans or C. neoformans cells. The tubes were incubated for $24-48 \mathrm{~h}$ at $36 \pm 1{ }^{\circ} \mathrm{C}$, and turbidity was read visually. MICs were calculated in comparison to growth control as the lowest concentration that shows inhibition for AMB, FLC, and the test compounds.

\section{General procedure for the mono-alkylation of the diynes}

To a stirred solution of the diyne (8.3-12.8 mmol) in dry THF (20-25 mL), $n$-Buli (2.5 M, 7.5$11.5 \mathrm{mmol})$ in dry hexane $(3.0-5.0 \mathrm{~mL})$ was added drop wise while keeping the temperature at $-78^{\circ} \mathrm{C}$. After $45 \mathrm{~min}$, HMPA $(3.0-5.0 \mathrm{~mL})$ and the bromoalkane $(7.7-11.5 \mathrm{mmol})$ were added drop wise to the reaction mixture while maintaining the temperature at $-78^{\circ} \mathrm{C}$. After 24 $\mathrm{h}$, the reaction mixture was worked up by pouring into a large volume of water, and extracting with diethyl ether $(2 \times 20 \mathrm{~mL})$. The organic layer was washed with brine $(1 \times 20 \mathrm{~mL})$ before drying $\left(\mathrm{MgSO}_{4}\right)$. Filtration, rotoevaporation of the solvent, and fractional distillation afforded the mono-alkylated diynes $\mathbf{2 a - 2 c}$ in $21-47 \%$ yields after purification by Kugel-Rohr distillation $\left(60-100^{\circ} \mathrm{C} / 3 \mathrm{~mm} \mathrm{Hg}\right)$ of the impurities.

a. 1,8-Pentadecadiyne ( $2 \boldsymbol{b}$ ) was obtained in a $21 \%$ yield as a viscous oil from the reaction of $1.22 \mathrm{~mL}$ of 1,8 -nonadiyne $(1.00 \mathrm{~g}, 8.32 \mathrm{mmol})$ and $1.16 \mathrm{~mL}$ of 1-bromohexane $(1.37 \mathrm{~g}, 8.32 \mathrm{mmol})$ according to the general procedure described above. IR (neat) $v_{\max } 3311,2932,2859,2118,1463,1332,1192,1100,629 \mathrm{~cm}^{-1 ; 1} \mathrm{H}-\mathrm{NMR}\left(\mathrm{CDCl}_{3}\right.$, $500 \mathrm{MHz}) \delta 2.19(2 \mathrm{H}, d t, J=2.6$ and $6.9 \mathrm{~Hz}, \mathrm{H}-10), 2.13(4 \mathrm{H}, \mathrm{m}, \mathrm{H}-3, \mathrm{H}-7), 1.93$ $(1 \mathrm{H}, t, J=2.6 \mathrm{~Hz}, \mathrm{H}-1), 1.57-1.24\left(14 \mathrm{H}, \mathrm{m},-\mathrm{CH}_{2}-\right), 0.88(3 \mathrm{H}, t, J=7.0 \mathrm{~Hz}$, $\mathrm{H}-15) ;{ }^{13} \mathrm{C}-\mathrm{NMR}\left(\mathrm{CDCl}_{3}, 125 \mathrm{MHz}\right) \delta 84.53(s, \mathrm{C}-2), 80.48(s), 79.84(s), 68.15(d$, C-1), $31.36(t, \mathrm{C}-13), 29.10(t), 28.61(t), 28.53(t), 28.04(t), 27.95(t), 22.56(t, \mathrm{C}-14)$, $18.73(t), 18.69(t), 18.33(t), 14.04(q, \mathrm{C}-15)$; GC-MS $m / z$ (relative intensity) $\mathrm{M}^{+} 204$ (0.1), 189 (1), 175 (4), 161 (4), 147 (14), 133 (28), 119 (32), 107 (11), 105 (54), 95 (13), $91\left(\mathrm{C}_{7} \mathrm{H}_{7}+, 100\right), 81$ (30), 79 (61), 67 (51), 55 (31).

(ii) 1,5-Pentadecadiyne (2a) was obtained in a $40 \%$ yield as a viscous oil from the reaction of $2.5 \mathrm{~mL}$ of 1,5 -hexadiyne $(1.00 \mathrm{~g}, 12.80 \mathrm{mmol})$ and $2.2 \mathrm{~mL}$ of 1 bromononane $(2.38 \mathrm{~g}, 11.50 \mathrm{mmol})$ according to the general procedure described above. IR (neat) $v_{\max } 3313,2926,2855,2122,1466,1338,1257,635 \mathrm{~cm}^{-1 ; 1} \mathrm{H}-\mathrm{NMR}$ $\left(\mathrm{CDCl}_{3}, 500 \mathrm{MHz}\right) \delta 2.38(4 \mathrm{H}, m, \mathrm{H}-3, \mathrm{H}-4), 2.14(2 \mathrm{H}, \mathrm{brt}, J=7.0 \mathrm{~Hz}, \mathrm{H}-7), 2.00$ $(1 \mathrm{H}, t, J=2.0 \mathrm{~Hz}, \mathrm{H}-1), 1.52-1.27\left(14 \mathrm{H}, m,-\mathrm{CH}_{2}-\right), 0.88(3 \mathrm{H}, t, J=6.9 \mathrm{~Hz}$, $\mathrm{H}-15) ;{ }^{13} \mathrm{C}-\mathrm{NMR}\left(\mathrm{CDCl}_{3}, 125 \mathrm{MHz}\right) \delta 83.11(s, \mathrm{C}-2), 81.61(s), 78.09(s), 68.94(d$, C-1), $31.89(t, \mathrm{C}-13), 29.50(t), 29.28(t), 29.16(t), 28.97(t), 28.83(t), 22.67(t, \mathrm{C}-14)$, $19.18(t), 18.93(t), 18.71(t), 14.09(q, \mathrm{C}-15)$; GC-MS $m / z$ (relative intensity) $\mathrm{M}^{+} 204$ (0.1), 161 (1), 147 (3), 133 (13), 119 (19), 109 (6), 105 (31), 95 (16), $91\left(\mathrm{C}_{7} \mathrm{H}_{7}+, 100\right)$, 81 (22), 79 (31), 67 (32), 65 (20), 55 (29).

(iii) 1,5-Octadecadiyne (2c) was obtained as a viscous oil in a $47 \%$ yield from the reaction of $2.5 \mathrm{~mL}$ of 1,5 -hexadiyne $(2.00 \mathrm{~g}, 12.80 \mathrm{mmol})$ and $1.8 \mathrm{~mL}$ of 1 bromododecane $(1.87 \mathrm{~g}, 7.70 \mathrm{mmol})$ according to the general procedure described above. IR (neat) $v_{\max } 3313,2925,2854,2122,1466,1338,1257,635 \mathrm{~cm}^{-1 ;}{ }^{1} \mathrm{H}-\mathrm{NMR}$ $\left(\mathrm{CDCl}_{3}, 500 \mathrm{MHz}\right) \delta 2.38(4 \mathrm{H}, m, \mathrm{H}-3, \mathrm{H}-4), 2.14(2 \mathrm{H}, \mathrm{brt}, J=6.9 \mathrm{~Hz}, \mathrm{H}-7), 2.00$ $(1 \mathrm{H}, m, \mathrm{H}-1), 1.55-1.26\left(20 \mathrm{H}, m,-\mathrm{CH}_{2-}\right), 0.88(3 \mathrm{H}, t, J=6.8 \mathrm{~Hz}, \mathrm{H}-18) ;{ }^{13} \mathrm{C}-\mathrm{NMR}$ $\left(\mathrm{CDCl}_{3}, 125 \mathrm{MHz}\right) \delta 83.11(\mathrm{~s}, \mathrm{C}-2), 81.62(s), 78.09(s), 68.93(d, \mathrm{C}-1), 31.92(t$, C-16), $29.67(t), 29.64(t), 29.63(t), 29.55(t), 29.35(t), 29.16(t), 28.97(t), 28.83$ 
$(t), 22.68(t, \mathrm{C}-17), 19.18(t), 18.93(t), 18.71(t), 14.10(q, \mathrm{C}-18)$; GC-MS $m / z$ (relative intensity) $\mathrm{M}^{+} 246$ (0.1), 175 (1), 161 (2), 147 (8), 133 (27), 119 (27), 105 (38), 95 (16), $91\left(\mathrm{C}_{7} \mathrm{H}_{7}+, 100\right), 81$ (20), 79 (35), 67 (28), 65 (24), 55 (29).

\section{General procedure for the carboxylation of the alkylated diynes}

To a stirred solution of the alkylated diynes (2a-2c, 1.7-4.6 mmol) in dry THF (17-46 mL), $n$-Buli (2.5 M, 2.6-7.2 mmol) in dry hexane (1-3 mL) was added drop wise while keeping the temperature approximately at $-78^{\circ} \mathrm{C}$. After 45 min the reaction mixture was treated with dry $\mathrm{CO}_{2}$ (by passing the $\mathrm{CO}_{2}$ through sulfuric acid) and left stirring for $24 \mathrm{~h}$. The reaction mixture was then worked up by pouring into a large volume of a saturated solution of ammonium chloride followed by extraction with diethyl ether (3 x $20 \mathrm{~mL})$. Rotoevaporation of the solvent afforded the diynoic acids $3 \mathbf{a}-3 \mathbf{c}$ in $28-52 \%$ yields after purification by Kugel-Rohr distillation $\left(60-100^{\circ} \mathrm{C} / 3 \mathrm{~mm} \mathrm{Hg}\right)$ of the impurities. The higher yield (52\%) was obtained for 2,9hexadecadiynoic acid $(\mathbf{3 b})$.

a. 2,9-Hexadecadiynoic acid ( $3 \boldsymbol{b}$ ) was obtained as an oil in a 52\% yield from the reaction of 1,8-pentadecadiyne $(0.35 \mathrm{~g}, 1.70 \mathrm{mmol})$ and excess dry $\mathrm{CO}_{2}$ (by passing the $\mathrm{CO}_{2}$ through sulfuric acid) according to the general procedure described above. IR (neat) $v_{\max } 3400-2900(b r), 2932,2859,2238,1688,1462,1410,1332,1279,1076$ $\mathrm{cm}^{-1 ;}{ }_{1} \mathrm{H}-\mathrm{NMR}\left(\mathrm{CDCl}_{3}, 500 \mathrm{MHz}\right) \delta 2.36(2 \mathrm{H}, t, J=7.1 \mathrm{~Hz}, \mathrm{H}-4), 2.14(4 \mathrm{H}, m, \mathrm{H}-8$, $\mathrm{H}-11), 1.62-1.23\left(14 \mathrm{H}, m,-\mathrm{CH}_{2}-\right), 0.88(3 \mathrm{H}, t, J=7.0 \mathrm{~Hz}, \mathrm{H}-16) ;{ }^{13} \mathrm{C}-\mathrm{NMR}$ $\left(\mathrm{CDCl}_{3}, 125 \mathrm{MHz}\right) \delta 157.08(s, \mathrm{C}-1), 92.01(s, \mathrm{C}-3), 81.24(s), 80.71(s), 72.69(s$, C-2), $31.35(t, \mathrm{C}-14), 29.08(t), 28.54(t), 28.43(t), 27.96(t), 26.98(t), 22.56(t, \mathrm{C}-15)$, $18.72(t), 18.69(t), 18.55(t), 14.04(q, \mathrm{C}-16)$.

(ii) 2,6-Hexadecadiynoic acid ( $3 a$ ) was obtained as a white solid in a $45 \%$ yield from the reaction of 1,5-pentadecadiyne $(0.94 \mathrm{~g}, 4.60 \mathrm{mmol})$ and excess dry $\mathrm{CO}_{2}$ (by passing the $\mathrm{CO}_{2}$ through sulfuric acid) according to the general procedure described above. M. p. $48-50^{\circ} \mathrm{C}$, IR (neat) $v_{\max } 3400-2900(b r), 2953,2915,2848,2246,1674$, $1469,1425,1300,1276,1075,890,608 \mathrm{~cm}^{-1 ; 1} \mathrm{H}-\mathrm{NMR}\left(\mathrm{CDCl}_{3}, 500 \mathrm{MHz},\right) \delta 2.54$ $(2 \mathrm{H}, b r t, J=7.3 \mathrm{~Hz}, \mathrm{H}-4), 2.44(2 \mathrm{H}, m, \mathrm{H}-5), 2.14(2 \mathrm{H}, t t, J=2.2$ and $7.1 \mathrm{~Hz}, \mathrm{H}-8)$, $1.47(2 \mathrm{H}, m, \mathrm{H}-9), 1.40-1.27\left(12 \mathrm{H}, m,-\mathrm{CH}_{2}-\right), 0.88(3 \mathrm{H}, t, J=6.9 \mathrm{~Hz}, \mathrm{H}-16) ;{ }^{13} \mathrm{C}-$ $\operatorname{NMR}\left(\mathrm{CDCl}_{3}, 125 \mathrm{MHz}\right) \delta 156.58(s, \mathrm{C}-1), 90.10(s, \mathrm{C}-3), 82.44(s), 77.10(s), 73.14$ $(s, \mathrm{C}-2), 31.83(t, \mathrm{C}-14), 29.48(t), 29.29(t), 29.15(t), 28.86(t), 28.83(t), 22.67(t$, C-15), 19.51 ( $t$, C-4), 18.67 ( $t$, C-8), 17.94 ( $t$, C-5), 14.08 ( $q$, C-16). Anal. calcd. for $\mathrm{C}_{16} \mathrm{H}_{24} \mathrm{O}_{2}: \mathrm{C}, 77.38 ; \mathrm{H}, 9.74$. Found: C, 76.17; H, 10.19.

(iii) 2,6-Nonadecadiynoic acid (3c) was obtained as a white solid in a $28 \%$ yield from the reaction of 1,5-octadecadiyne $(0.89 \mathrm{~g}, 3.60 \mathrm{mmol})$ and excess dry $\mathrm{CO}_{2}$ (by bubbling the $\mathrm{CO}_{2}$ through sulfuric acid) according to the general procedure described above. M. p. $62-64^{\circ} \mathrm{C}$, IR (neat) $v_{\max } 3400-2900$ (br), 2953, 2916, 2848, 2245, 1671, $1422,1280,912,720 \mathrm{~cm}^{-1 ;}{ }_{1} \mathrm{H}-\mathrm{NMR}\left(\mathrm{CDCl}_{3}, 500 \mathrm{MHz}\right) \delta 2.54(2 \mathrm{H}, b r t, J=7.4 \mathrm{~Hz}$, $\mathrm{H}-4), 2.44(2 \mathrm{H}, m, \mathrm{H}-5), 2.14(2 \mathrm{H}, t t, J=2.3$ and $7.1 \mathrm{~Hz}, \mathrm{H}-8), 1.47(2 \mathrm{H}, m, \mathrm{H}-9)$, $1.38-1.25\left(18 \mathrm{H}, m,-\mathrm{CH}_{2}-\right), 0.88(3 \mathrm{H}, t, J=6.9 \mathrm{~Hz}, \mathrm{H}-19) ;{ }^{13} \mathrm{C}-\mathrm{NMR}\left(\mathrm{CDCl}_{3}, 75\right.$ MHz) $\delta 156.96(s, \mathrm{C}-1), 90.33(s, \mathrm{C}-3), 82.44(s), 77.21(s), 73.06(s, \mathrm{C}-2), 31.91(t$, C-17), $29.64(t), 29.53(t), 29.35(t), 29.14(t), 28.84(t), 22.68(t, C-18), 19.49(t$, C-4), $18.66(t, \mathrm{C}-8), 17.91(t, \mathrm{C}-5), 14.11$ ( $q, \mathrm{C}-19)$. Anal. calcd. for $\mathrm{C}_{19} \mathrm{H}_{30} \mathrm{O}_{2}: \mathrm{C}, 78.57$; H, 10.41. Found: C, 77.14; H, 10.40.

\section{RESULTS AND DISCUSSION}

Seven acetylenic fatty acids were synthesized and evaluated for antifungal activities against C. albicans and C. neoformans. The acetylenic fatty acids 2-hexadecynoic acid, 5-

hexadecynoic acid, 9-hexadecynoic acid, and 6-nonadecynoic acid were synthesized according 
to the previously described procedures $(1,8,15)$. Despite the fact that the 2,6 -octadecadiynoic acid has been previously synthesized (10-11), there are no reported syntheses for acids 3a-3c. Therefore, a simple synthetic methodology for the preparation of novel fatty acids 3a-3c was developed based on two consecutive acetylide coupling reactions.

The synthesis of the dimethylene-interrupted 2,6-hexadecadiynoic acid (3a) and 2,6nonadecadiynoic acid (3c) was conveniently accomplished using 1,5 -hexadiyne (50\% in pentane) as the starting material (Scheme 1). In the preparation of 3a, 1,5-hexadiyne was coupled with 1-bromononane using $n$-BuLi in THF/HMPA at $-78^{\circ} \mathrm{C}$, which afforded $1,5-$ pentadecadiyne (2a) in a $40 \%$ yield. Likewise, for the synthesis of acid $\mathbf{3 c}$, the 1,5-hexadiyne was coupled with 1-bromododecane using the above mentioned acetylide coupling conditions, which afforded 1,5-octadecadiyne (2c) in a 47\% yield after final purification (Scheme 1). Coupling of the lithium acetylides of 1,5-pentadecadiyne (2a) or the 1,5-octadecadiyne (2c) with carbon dioxide and subsequent protonation with ammonium chloride afforded the 2,6hexadecadiynoic acid (3a) or the 2,6-nonadecadiynoic acid (3c) in $28-45 \%$ yields after final purification (Scheme 1). The overall yields for these two two-step syntheses ranged between 13 and $18 \%$.

The preparation of 2,9-hexadecadiynoic acid (3b) followed a similar synthetic strategy, with the exception that this synthesis started with the 1,8-nonadiyne. The diyne was coupled with 1-bromohexane using again $n$ - $\mathrm{BuLi}$ in THF/HMPA at $-78^{\circ} \mathrm{C}$, which afforded 1,8 pentadecadiyne (2b) in a $21 \%$ yield after final purification. Final coupling of the lithium acetylide of 1,8-pentadecadiyne (2b) with carbon dioxide and subsequent protonation with ammonium chloride afforded the desired 2,9-hexadecadiynoic acid (3b) in a $52 \%$ yield after final purification (Scheme 1). The overall yield for this two-step synthesis was $11 \%$.

The antifungal activity of the synthesized acetylenic fatty acids against Candida albicans strains ATCC 14053 and ATCC 60193, and Cryptococcus neoformans ATCC 66031 in SDB media were determined using a modified method of the National Committee for Clinical Laboratory Standards (NCCLS) as described by Galgiani and the more recent NCCLS M27A microdilution methods as described previously (12-13) (Table 1). Amphotericin B (AMB) and fluconazole (FLC) were used as positive controls. Among the monoynoic fatty acids, the acid 2-hexadecynoic acid exhibited the best minimum inhibitory (MIC) values against fluconazole resistant $C$. albicans ATCC 14053 and ATCC 60193 strains with MIC values between 9.4 and $100 \mu \mathrm{M}$, respectively. However, as we have previously reported (8), 6nonadecynoic acid showed the best MIC values $(<4.3 \mu \mathrm{M})$ against $C$. neoformans ATCC 66031, but it was not very effective against the fluconazole resistant $C$. albicans strains studied herein (8). Therefore, introduction of a triple bond at either C-2 or C-6 in the alkyl chain was effective in increasing the fungitoxicity of the fatty acid. However, a triple bond at either C-5 or C-9 in the alkyl chain was not particularly effective in increasing the fungitoxicity of the fatty acids.

Among the studied diynoic fatty acids, 2,6-hexadecadiynoic acid (3a) displayed the best MIC values against both the fluconazole resistant C. albicans ATCC 14053 and ATCC 60193 strains with MIC values of $11.5 \mu \mathrm{M}$. However, 2,6-nonadecadiynoic acid (3c) displayed the best MIC values $(<5.0 \mu \mathrm{M})$ among the diynoic acids against $C$. neoformans ATCC 66031, but it displayed modest activity against the studied fluconazole resistant $C$. albicans strains with MIC values between 20 and $80 \mu \mathrm{M}$ (Table 1). A comparison of the bioactivity of 3a with that of the 2-hexadecynoic acid reveals that introduction of a second triple bond at C-6 increases the fungitoxicity of the acid towards C. albicans ATCC $60193(\mathrm{MIC}=11.5 \mu \mathrm{M})$ approximately 9 fold compared to 2-hexadecynoic acid $(\mathrm{MIC}=100 \mu \mathrm{M})$. Therefore, the diynoic acid 3a has the potential of displaying a broader antifungal profile than the parent 2-hexadecynoic acid. 
The acid 2,9-hexadecadiynoic acid (3b) was also studied and it was not particularly effective against the fluconazole resistant $C$. albicans strains studied herein, but it displayed fungitoxicity against $C$. neoformans ATCC 66031 with a MIC of $<5.8 \mu \mathrm{M}$. A comparison of the bioactivity of $\mathbf{3 b}$ with that of the 9-hexadecynoic acid reveals that introduction of a second triple bond at C-2 increases the fungitoxicity of the parent 9-hexadecynoic acid against the three fungal strains studied, but the bioactivity of $\mathbf{3 b}$ was still poor as compared to that of either $3 \mathbf{a}$ or $3 \mathbf{c}$.

In order to determine the selectivity of the 2,6-hexadecadiynoic acid (3a) towards fungi (eukaryotic pathogens) vs. bacteria we chose to explore the antimycobacterial activity of both 3a and the 2-hexadecynoic acid towards Mycobacterium tuberculosis $\mathrm{H}_{37} \mathrm{Rv}$ following a procedure previously described (16). We decided on M. tuberculosis since there is a recent literature report indicating that the 2-hexadecynoic acid can be toxic (MIC's $\sim 10-20 \mu \mathrm{M}$ in Sauton's medium) to mycobacteria by the accumulation of two metabolites, i.e., the 3ketohexadecanoic acid, which blocks fatty acid biosynthesis, and 3-hexadecynoic acid, an inhibitor of fatty acid $\beta$-oxidation (17). The 2-hexadecynoic acid, therefore, can inhibit mycolic acid biosynthesis, fatty acid biosynthesis, and fatty acid degradation ( $\beta$-oxidation) pathways of importance for mycobacteria (17).

Our antimycobacterial results are shown in Table 2. Two assays were used to study the antimycobacterial activity of the acetylenic fatty acids, i.e., the microplate alamar blue assay (MABA) and the low oxygen recovery assay (LORA). The MABA is the "normal" MIC determination against replicating $M$. tuberculosis under aerobic conditions for 8 days. On the other hand, the LORA utilizes $M$. tuberculosis under anaerobic non-replicating conditions for 11 days. As can be seen from Table 2, both acetylenic fatty acids displayed similar MIC's of around 140-145 $\mu \mathrm{M}$ (in Middlebrook 7H12 medium) against M. tuberculosis using the MABA assay, but also both acids were not inhibitory to non-replicating and persistent $M$.

tuberculosis, as determined by the LORA assay (16). From these experiments we can conclude that the additional $\Delta 6$ triple bond in $\mathbf{3 a}$ does not help in increasing its antimycobacterial activity as compared to the 2-hexadecynoic acid, a fact that supports its postulated mechanism of action (17). However, it is evident that acid $\mathbf{3 a}$ is a better antifungal agent than an antimycobacterial agent for its specificity towards fungal cells, since the additional $\Delta 6$ triple bond in 3a makes a difference in the antifungal activity.

With respect to the toxicity of the 2-alkynoic acids it was recently demonstrated that 2-alkynoic acids could be used specifically against bacteria without toxicity to their host due to the fact that the FASI complex in microsomal systems is not inhibited by the 2-alkynoic acids (17). In addition, it was previously reported that despite the fact that the 2-hexadecynoic acid inhibits the growth of HeLa cells, the simultaneous addition of palmitic acid to the culture medium reverses the growth inhibition observed in HeLa cells, thus implying that toxicity would not occur in animals consuming a normal diet (3).

Further experiments are required to determine the mechanism of antifungal activities by these novel 2,6-diynoic FA. One possible mechanism of action for the 2,6-diynoic FA is isomerization to a 2,3-allene (as the CoA derivative) and subsequent inhibition of the biosynthesis of the fungal fatty acids as shown for the 2-hexadecynoic acid in intact animals (4). Likewise, also analogous to the suspected mechanism of action for the 6-nonadecynoic acid, the 2,6-diynoic FA could also inhibit sphingolipid biosynthesis in these fungi (7). Both mechanisms of lipid biosynthesis inhibition could also be operative, thus explaining the enhanced activity of 3a. Compound 3a has the potential for further evaluation in topical formulations for the treatment of fungal infections, as antifungal in wound dressings, or as a preservative in skin and hair care products. 


\section{Acknowledgements}

This work was supported by a grant from the SCORE program of the National Institutes of Health (grant no. S06GM08102). D. Sanabria thanks the NSF-AGEP (Alliance for Graduate Education and the Professoriate) program for a graduate fellowship. We thank Marlenne Mulero and Lizabeth Giménez for technical assistance in the synthesis of the acetylenic fatty acids. This research was also supported in part by NIH Grant Numbers P20RR16457 and P20RR16470 from the BRIN/INBRE program of the National Center for Research Resources.

\section{References}

1. Gershon H, Shanks L. Antifungal Properties of 2-Alkynoic Acids and their Methyl Esters. Can J Microbiol 1978;24:593-597. [PubMed: 26458]

2. Gershon, H.; Shanks, L. Antifungal Activity of Fatty Acids and Derivatives: Structure Activity Relationships. In: Kabara, JJ., editor. The Pharmacological Effect of Lipids. American Oil Chemical Society; Champaign, Illinois: 1978. p. 51-62.

3. Konthikamee W, Gilbertson JR, Langkamp H, Gershon H. Effect of 2-Alkynoic Acids on In Vitro Growth of Bacterial and Mammalian Cells. Antimicrob Agents Chemother 1982;22:805-809. [PubMed: 7181490]

4. Wood R, Lee T. Metabolism of 2-Hexadecynoate and Inhibition of Fatty Acid Elongation. J Biol Chem 1981;256:12379-12386. [PubMed: 7298663]

5. Upreti GC, Matocha M, Wood R. Effect 2-Hexadecynoic acid on Cultured 7288C Hepatoma Cells. Lipids 1981;16:315-322. [PubMed: 7253840]

6. Rudnik DA, Lu T, Jackson-Machelski E, Hernandez JC, Li Q, Gokel GW, Gordon JI. Analogs of Palmitoyl-CoA that are Substrates for Myristoyl-CoA: Protein $N$-Myristoyltransferase. Proc Natl Acad Sci USA 1992;89:10507-10511. [PubMed: 1438240]

7. Li XC, Jacob MR, ElSohly HN, Nagle DG, Smillie TJ, Walker LA, Clark AM. Acetylenic Acids Inhibiting Azole-Resistant Candida albicans from Pentagonia gigantifolia. J Nat Prod 2003;66:11321135. [PubMed: 12932143]

8. Carballeira NM, Sanabria D, Parang K. Total Synthesis and Further Scrutiny of the in vitro Antifungal Activity of 6-Nonadecynoic Acid. Arch Pharm 2005;338:441-443.

9. Wille JJ, Kydonieus A. Palmitoleic Acid Isomer (C16:1 delta6) in Human Skin Sebum is Effective against Gram-Positive Bacteria. Skin Pharmacol Appl Skin Physiol 2003;16:176-187. [PubMed: 12677098]

10. Lie Ken Jie MSF, Lam CH. Fatty Acids. Part XVI The Synthesis of all Isomeric C18 Furan-Containing Fatty Acids. Chem Phys Lipids 1978;21:275-287.

11. Lam CH, Lie Ken Jie MSF. Fatty Acids. IV Synthesis of all the Dimethylene-Interrupted Methyl Octadecadiynoates and a Study of their Gas-Liquid Chromatographic Properties. J Chromatogr 1975;115:559-570. [PubMed: 1206065]

12. Galgiani JN. Susceptibility Testing of Fungi: Current Status of the Standardization Process. Antimicrob Agents Chemother 1993;37:2517-2521. [PubMed: 8109912]

13. Carballeira NM, Ortiz D, Parang K, Sardari S. Total Synthesis and In Vitro-Antifungal Activity of (+/-)-2-Methoxytetradecanoic Acid. Arch Pharm (Weinheim) 2004;337:152-155. [PubMed: 15038060]

14. Nam NH, Sardari S, Selecky M, Parang K. Carboxylic Acid and Phosphate Ester Derivatives of Fluconazole: Synthesis and Antifungal Activities. Biorg Med Chem 2004;12:6255-6269.

15. Ames DE, Covell AN. Synthesis of Long-Chain Acids. III Synthesis of Acetylenic Acids. J Chem Soc 1963:775-778.

16. Carballeira NM, Cruz H, Kwong CD, Wan B, Franzblau S. 2-Methoxylated Fatty Acids in Marine Sponges: Defense Mechanism Against Mycobacteria? Lipids 2004;39:675-680. [PubMed: 15588025]

17. Morbidoni HR, Vilcheze C, Kremer L, Bittman R, Sacchettini JC, Jacobs WR Jr. Dual Inhbition of Mycobacterial Fatty Acid Biosynthesis and Degradation by 2-Alkynoic Acids. Chem Biol 2006;13:297-307. [PubMed: 16638535] 


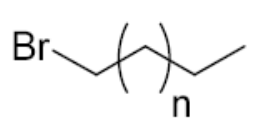

$1 \mathrm{a}, \mathrm{n}=6$

$1 \mathrm{~b}, \mathrm{n}=3$

1c, $n=9$

i) n-BuLi, THF, $-78^{\circ} \mathrm{C}, \mathrm{HMPA} ; \mathrm{CO}_{2}$

ii) $\mathrm{NH}_{4} \mathrm{Cl}$

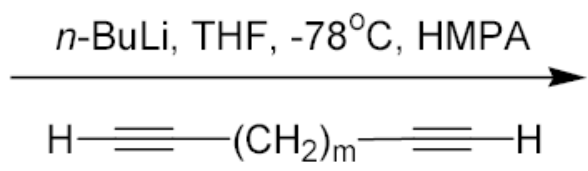

$$
\mathrm{m}=2 \text { or } 5
$$

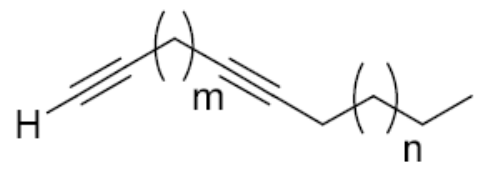

2a, $m=2 ; n=6$

$2 b, m=5 ; n=3$

$2 \mathrm{c}, \mathrm{m}=2 ; \mathrm{n}=9$

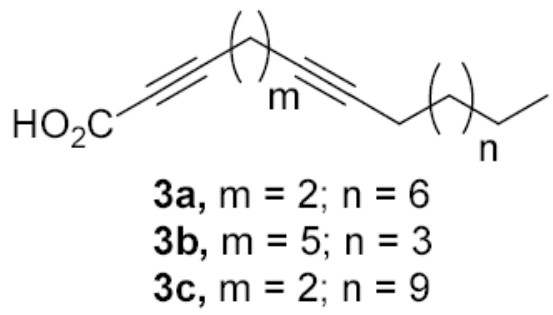

Scheme 1. 
TABLE 1

Antifungal activity (MIC values, $\mu \mathrm{M}$ ) against Candida albicans (SDB) and Cryptococcus neoformans (SDB) at $35-37^{\circ} \mathrm{C}$ after $24-48 \mathrm{~h}^{a}$

\begin{tabular}{lccc}
\hline Compound & & MIC $(\boldsymbol{\mu M})$ \\
\hline & C. albicans ATCC 14053 & C. albicans ATCC 60193 & C. neoformans ATCC 66031 \\
2-Hexadecynoic & 9.4 & 100.3 & $<6.3$ \\
5-Hexadecynoic & 7845 & 10460 & 61.3 \\
9-Hexadecynoic & 8260 & 8896 & 11.5 \\
6-Nonadecynoic & 6672 & 2235 & 8.8 \\
2,6-Hexadecadiynoic (3a) & 11.5 & 80.2 & $<.3$ \\
2,9-Hexadecadiynoic (3b) & 4469 & $>1000$ \\
2,6-Nonadecadiynoic (3c) & 20.0 & $<0.3$ & $<5.7$ \\
FLC & $>2000$ & $>5000$ & $<5.0$ \\
AMB & $<0.3$ & $<0.9$ \\
DMSO & $>5000$ & $>5000$
\end{tabular}

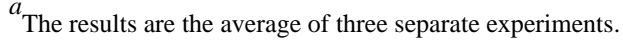


TABLE 2

Minimum Inhibitory Concentrations (MIC values, $\mu \mathrm{M}$ ) of 2,6-Hexadecadiynoic acid (3a) and 2-Hexadecynoic acid Against Mycobacterium tuberculosis $\mathrm{H}_{37} \mathrm{Rv}^{a}$

\begin{tabular}{lcc}
\hline Compound & MIC $(\boldsymbol{\mu M})$ & \\
\hline & MABA & LORA \\
2,6-Hexadecadiynoic (3a) & 145 & $>300$ \\
2-Hexadecynoic & 141 & $>300$ \\
Rifampin & 0.08 & 1.5 \\
\\
\hline
\end{tabular}

$a$ MABA, microplate alamar blue assay; LORA, low oxygen recovery assay. 